\title{
Gross and Microscopic Lesions of the Ovaries of Camels from Abattoirs in Eastern Province of Kingdom of Saudi Arabia
}

\author{
Adel I. Al-Afaleq1 ${ }^{1}$, Abdel Gadir Musa Homeida², Seif Eldawla Mustafa Barakat $^{3 *}{ }^{(0)}$, \\ Mohamed Salim Moqbel ${ }^{4}$ \\ ${ }^{1}$ College of Public Health, Imam Abdulrahman Bin Faisal University, Dammam, KSA \\ ${ }^{2}$ Department of Biology, College of Science, Imam Abdulrahman Bin Faisal University, Dammam, KSA \\ ${ }^{3}$ Department of Anatomy, College of Veterinary Medicine, King Faisal University, Al-Ahsa, KSA \\ ${ }^{4}$ Department of Pathology, College of Veterinary Medicine, King Faisal University, Al-Ahsa, KSA \\ Email: *seifbrkt@gmail.com
}

How to cite this paper: Al-Afaleq, A.I., Homeida, A.G.M., Barakat, S.E.M. and Moqbel, M.S. (2022) Gross and Microscopic Lesions of the Ovaries of Camels from Abattoirs in Eastern Province of Kingdom of Saudi Arabia. Open Journal of Patholo$g y, 12,1-11$.

https://doi.org/10.4236/ojpathology.2022.1 $\underline{21001}$

Received: August 12, 2020

Accepted: November 20, 2021

Published: November 23, 2021

Copyright $\odot 2022$ by author(s) and Scientific Research Publishing Inc. This work is licensed under the Creative Commons Attribution International License (CC BY 4.0).

http://creativecommons.org/licenses/by/4.0/

\section{(c) (i) Open Access}

\begin{abstract}
In the present investigation, gross and microscopic lesions of the ovaries were studied in two hundred and ten (210) adult non-pregnant she-camels. Fresh samples of ovaries were collected from she-camels at the point of slaughter in Al-Ahsa abattoir, Eastern region of Kingdom of Saudi Arabia. These samples were subjected to histopathological studies and stained by routine Hematoxylin and Eosin stain. Grossly, of the 210 ovarian tissues examined, 30 (14.28\%) had ovarian lesions of one type or another, whereas 180 (85.71\%) camels were apparently healthy. Only $6(2.85 \%)$ ovaries showed unilateral ovarian hypoplasia, whereas 4 (1.9\%) showed bilateral ovarian hypoplasia. Cystic ovaries were observed in a total of 13 of the collected samples of ovaries, of these $8(3.8 \%)$ were diagnosed as follicular cystic ovaries, while $5(2.38 \%)$ were luteal cystic ovaries. Ovarian abscess appeared in only one sample of the collected ovaries. While ovarian tumors were observed in a total of 6 of the collected samples distributed as, two fibromas, three dermoid cysts, and only one hemangioma. The present study indicates that follicular cysts, luteal cysts and ovarian hypoplasia were the most common ovarian disorders in non-pregnant she-camels in Al-Ahsa region of the Eastern Province of Kingdom of Saudi Arabia.
\end{abstract}

\section{Keywords}

Dromedary Camel, Ovarian Lesions, Saudi Arabia

\section{Introduction}

Compared to other animals, camels are considered the best in coexistence, re- 
production and production under the harsh desert environmental conditions [1] [2]. As in all types of livestock, their exposure to infections in the reproductive system causes infertility or low fertility [3] [4] [5] [6] [7].

Reproductive efficiency in camelidae is considered low [8] [9]. It has been reported that calving rates rarely exceed $40 \%$ in travelling herds and $70 \%$ in more intensively managed herds [10]. Thus, identification of reproductive diseases is important, especially when dealing with genetically superior animals. The etiology, epidemiology, clinical aspects pathology, diagnosis and treatment of many diseases in camelids have been extensively studied [11]. However, only few research workers have studied the forms and incidence of ovarian disorders [12] [13] [14] [15]. Previous reports have investigated the pathological disorders of the female reproductive system, of camels [3] [6] [16]. The aim of the present study was to determine the incidence rates of ovaries disorders of camels, in Al-Ahsa region in Eastern Province of Kingdom of Saudi Arabia, and to describe their gross and microscopic lesions.

\section{Materials and Methods}

The ovaries of 210 apparently healthy adult she-camels were studied for gross and microscopic lesions after slaughter at Al-Ahsa abattoirs. For histopathological technique, all samples were fixed in $10 \%$ neutral formalin, embedded in paraffin, sectioned and stained with Hematoxylin and Eosin (H\&E) according to [17].

\section{Results}

\subsection{Pathological Manifestations}

\subsubsection{Hypoplastic Ovaries}

Grossly out of 210 ovarian tissues examined, 6 (2.85\%), showed unilateral hypoplasia, whereas $4(1.95 \%)$, had bilateral hypoplasia (Table 1$)$. The affected ovaries were small in size and devoid of any signs of ovulation (Figure 1). The microscopic examination of the hypoplastic ovaries revealed the presence of atrophy in the cortex of the ovaries, which was formed from connective tissue and blood vessels. In addition, all the affected ovaries were free of oocytes and did not show any stage of follicular formation (Figure 2).

\subsubsection{Ovarian Cysts}

\section{1) Follicular cysts:}

Grossly out of 210 ovarian tissues examined 8 (3.8\%), showed follicular cysts. These cysts were either multiple or single (Figure 3 ) and averaged 3 to $5 \mathrm{~cm}$ in diameter. The follicular cysts also contained a clear, yellowish fluid, but some of them contained a bloody or coagulated fluid (Figure 4). The microscopic examination showed that the follicular cysts are lined with granulosa cells and their number of layers varied from case to case. The large cysts were lined with granulosa cells of 1 - 2 layers (Figure 5 and Figure 6). 
Table 1. Shows the numbers and proportions of pathological lesions of ovaries of camels $(\mathrm{n}=210)$.

\begin{tabular}{ccc}
\hline Type of Infection & Number $(\mathrm{n})$ & Percentage $\%$ \\
\hline Ovarian Hypoplasia & 6 & \\
Unilateral & 4 & 2.85 \\
Bilateral & & 1.95 \\
Cystic Ovaries & 8 & 3.8 \\
Follicular & 5 & 2.38 \\
Luteal & 1 & 0.476 \\
Ovarian Abscesses & & \\
Ovarian Tumors & 2 & 0.952 \\
Fibroma & 3 & 1.42 \\
Dermoid Cyst & 1 & 0.470 \\
Hemangioma & 30 & 14.28 \\
\hline Total & &
\end{tabular}

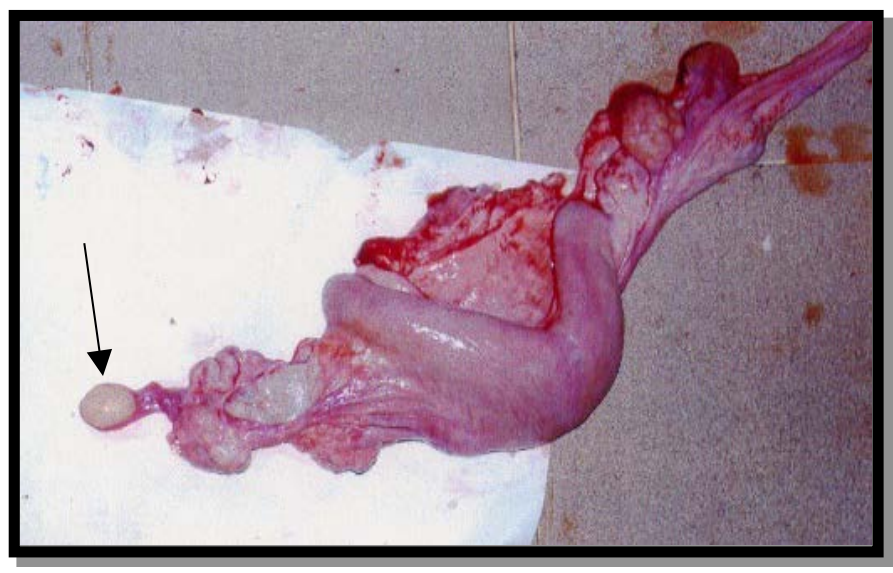

Figure 1. Hypoplastic ovaries; the ovaries were small in size and devoid of any signs of ovulation.

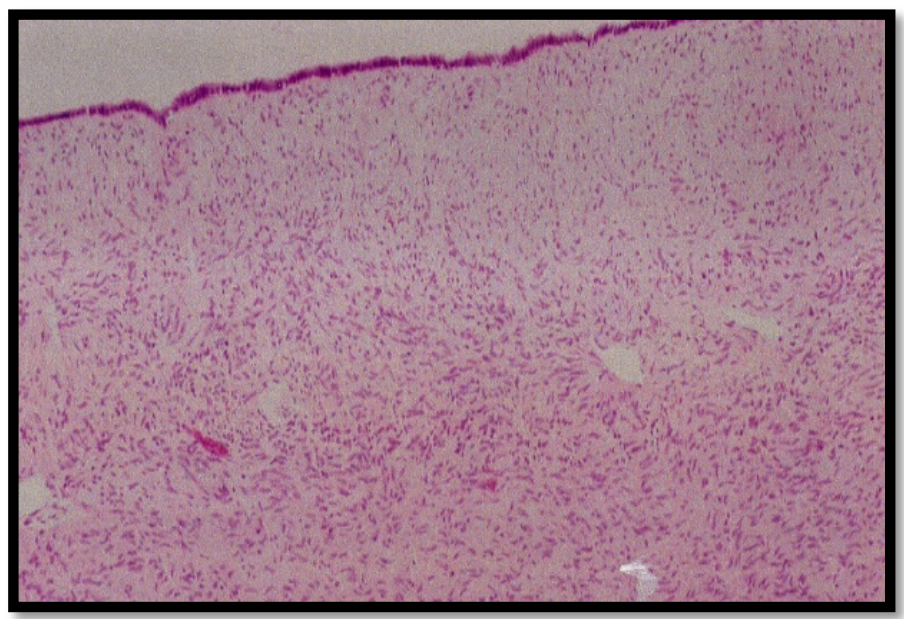

Figure 2. Hypoplastic ovaries; atrophy in the cortex of the ovaries, which is formed from connective tissue and blood vessel. 


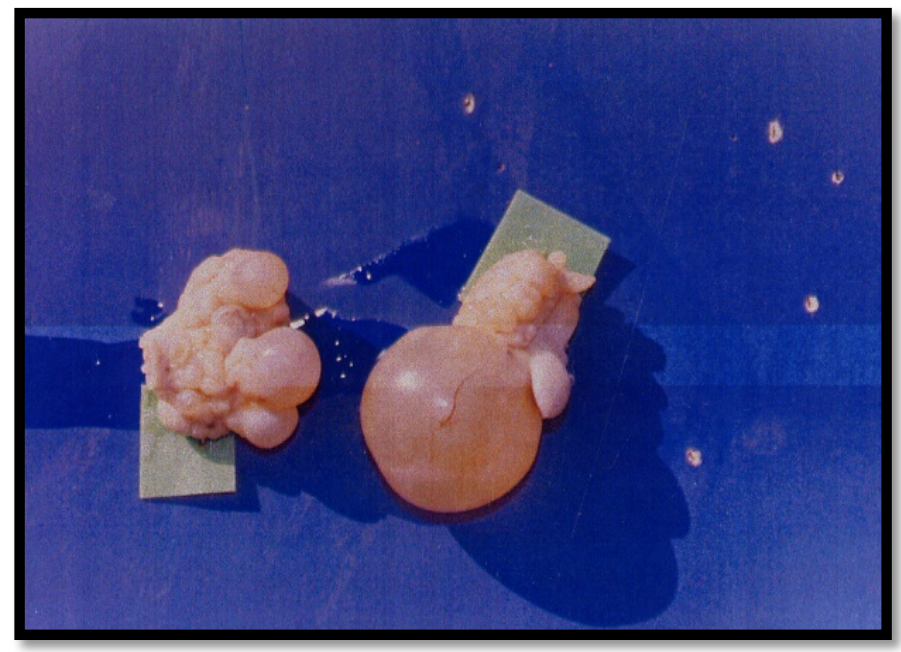

Figure 3. A follicular cyst and multiple cyst containing transparent fluid.

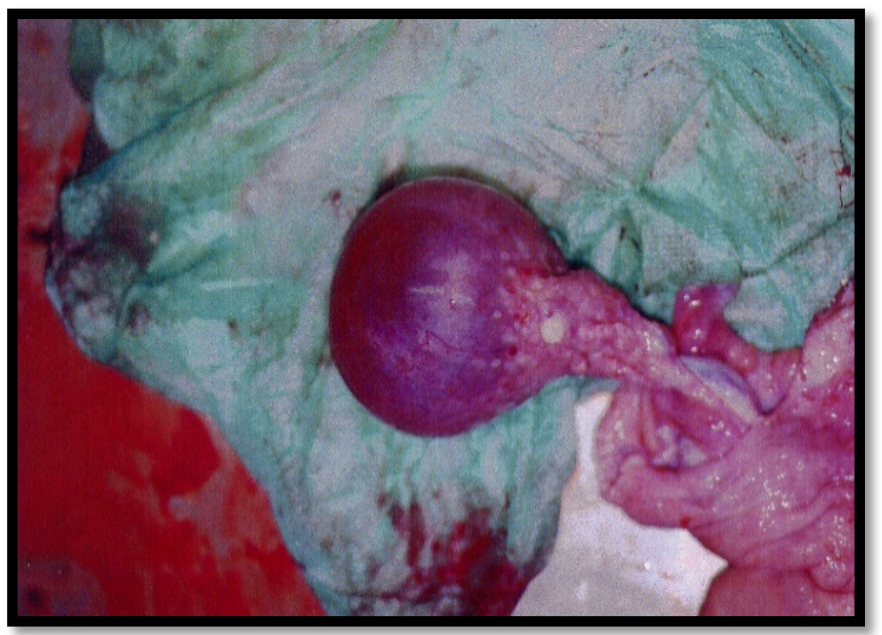

Figure 4. A follicular cyst containing a bloody fluid. Hemorrhagic follicle.

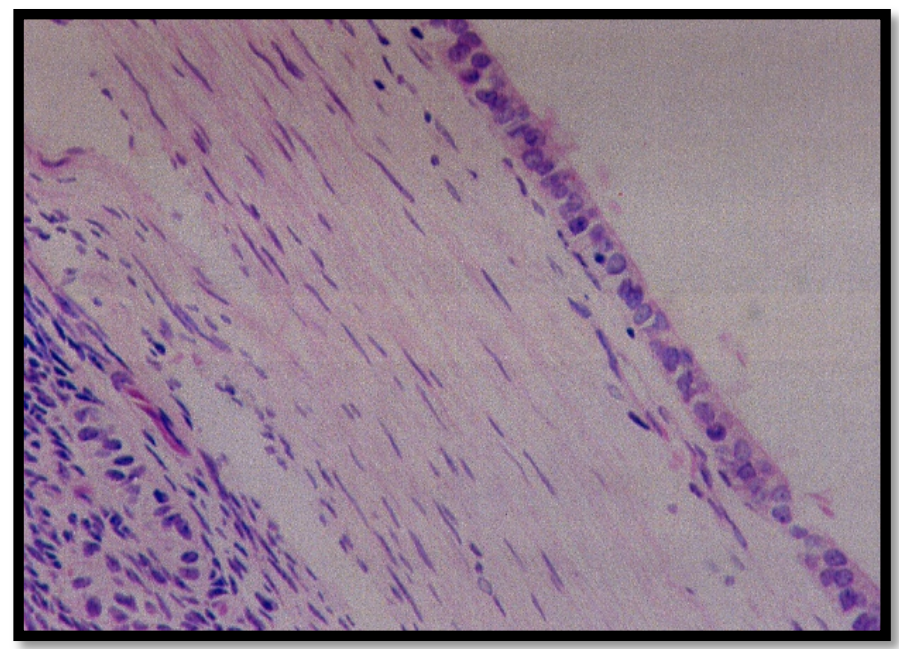

Figure 5. Follicular cyst (more than $5 \mathrm{~cm}$ ). Note that it is lined with one layer of granulosa cells. 


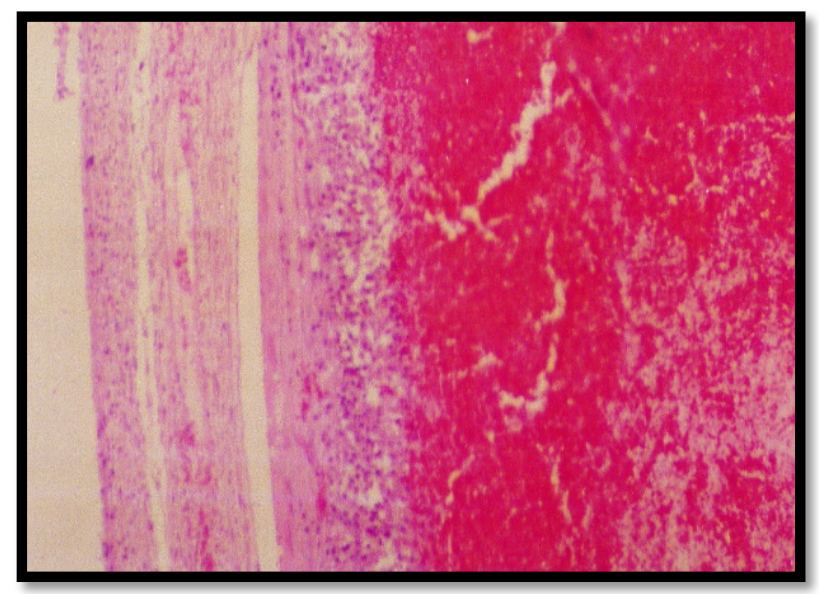

Figure 6. Hemorrhagic follicular cyst. Note the presence of blood clot.

\section{2) Luteal cysts:}

The luteal cysts were prominent on the surface of the ovary, and were dark red, with a coaxial cavity filled with a clear white fluid (Figure 7). The central cavity was surrounded by connective tissue and many luteal cells, and these cells have been active and vacuolated. Numerous capillaries appeared between cells (Figure 8).

\subsubsection{Ovarian Tumors}

\section{1) Fibroma}

The tumors were prominent on the surface as solid round blocks of $1-2 \mathrm{~cm}$. Microscopy revealed that the tumors consisted of fibroblasts and collagen fibers in the form of arranged bundles running in different directions.

\section{2) Dermoid cyst}

The tumor began as a prominent cyst on the surface of the ovary ranging from 1 to $2 \mathrm{~cm}$. The surface section showed that the cyst contains hair and grease surrounded by a thick wall (Figure 9). Microscopic examination showed the wall was lined with layers of epithelial cells, while the dermis layer contains wax and sweat glands, hair bulbs and hyaline cartilage (Figure 10(a) and Figure 10(b)).

\section{3) Plexiform hemangioma}

The tumor represents a prominent mass on the surface of the ovary, solid and brownish (Figure 11). Microscopic examination revealed that the tumor consists of contiguous blood vessels interspersed with fibrous tissue of fibroblasts and collagen fibers (Figure 12).

\subsubsection{Ovarian Purulent Inflammation (Ovarian Abscess)}

Ovarian hypertrophy was observed, and the cross-section indicated the presence of a viscous pus covering all the area of the ovary and surrounded from the outside by a thick fibrous wallet. Ovarian adhesion to the follicle was also observed (Figure 13). The cross-sectional sector showed the presence of a viscous pus covered all the area of the ovary and surrounded from the outside with a thick fibrous wallet. 


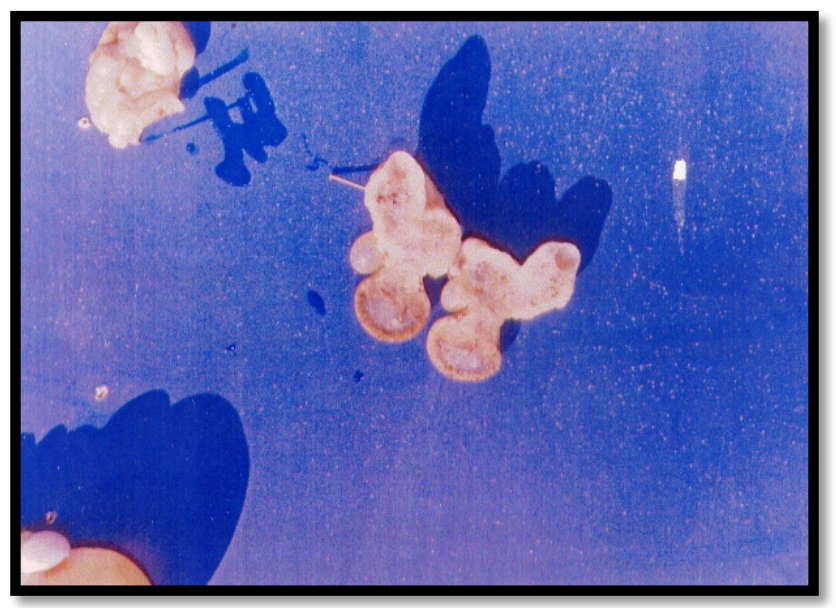

Figure 7. The luteal cysts were prominent on the surface of the ovary, and were dark red, with a coaxial cavity filled with a clear white fluid.

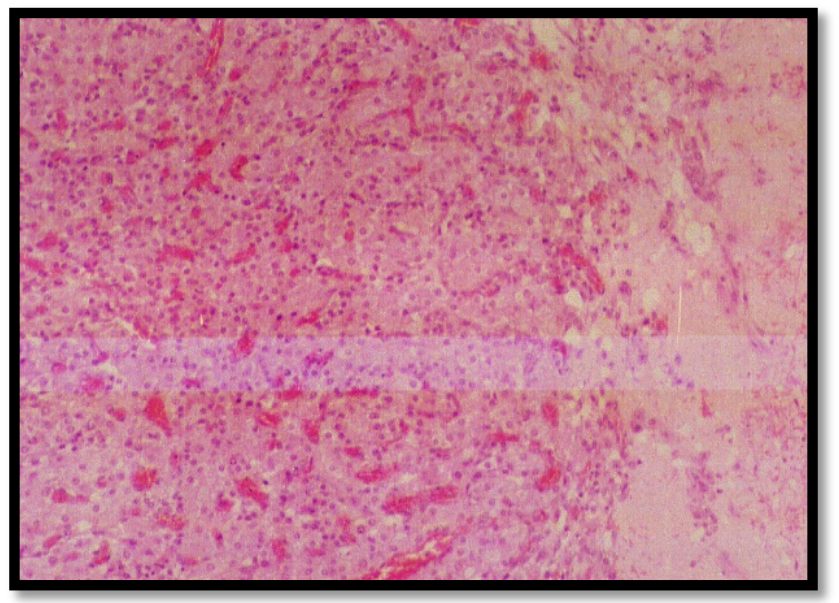

Figure 8 . Section in luteal sacs. Note that the cavity is surrounded by a fibrous tissue and then a number of multiple lutein cells $\times 200$.

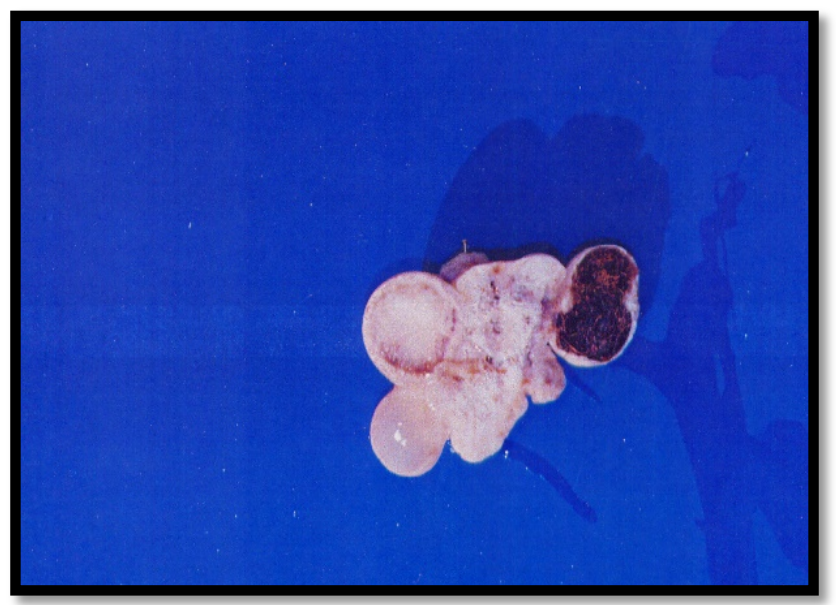

Figure 9. Dermoid cyst. The tumor began as a prominent cyst on the surface of the ovary ranging from 1 to $2 \mathrm{~cm}$. The surface section showed that the cyst contains hair and grease surrounded by a thick wall. 


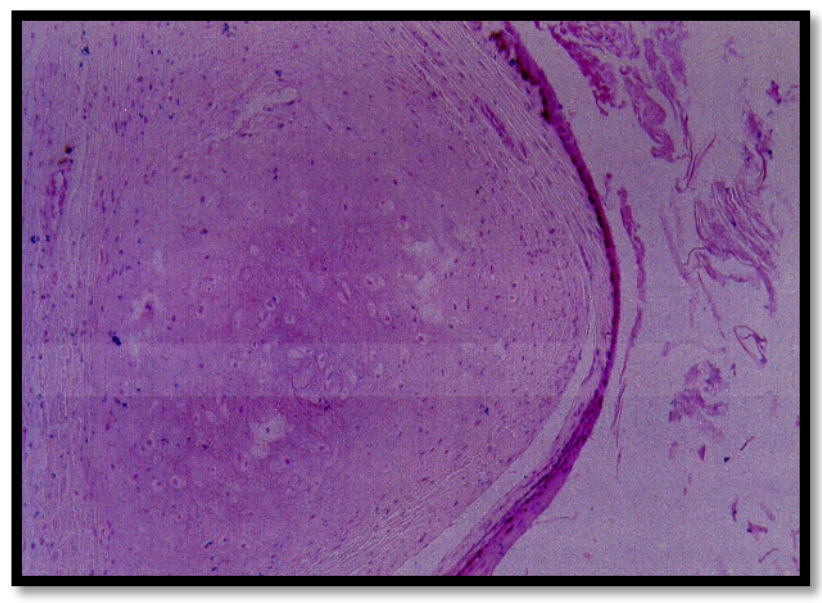

(a)

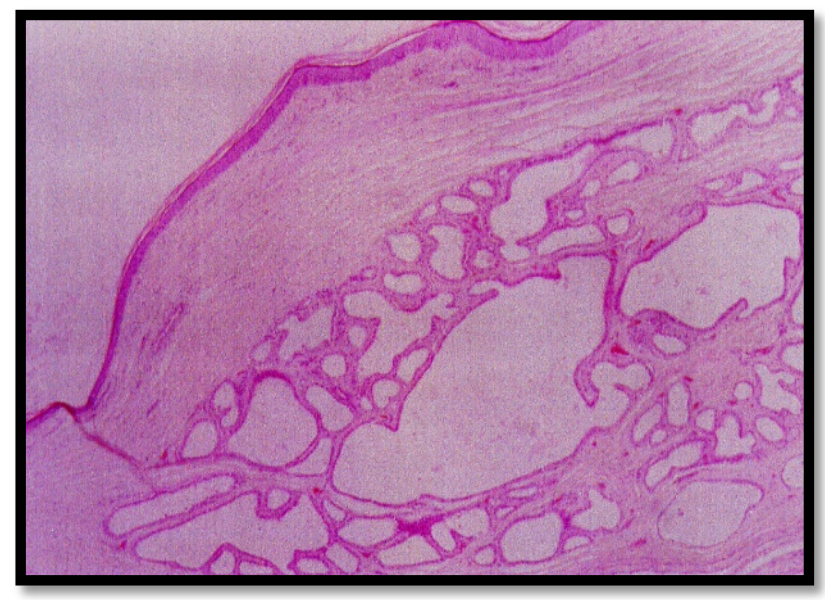

(b)

Figure 10. (a) C.S. in the dermoid cyst. Note the presence of hyaline cartilages with the formation of the wall, $\times 50$; (b) C.S. in the dermoid cyst. The wall was lined with layers of epithelial cells, while the dermis layer contains wax and sweat glands, hair bulbs and hyaline cartilage, $\times 50$.

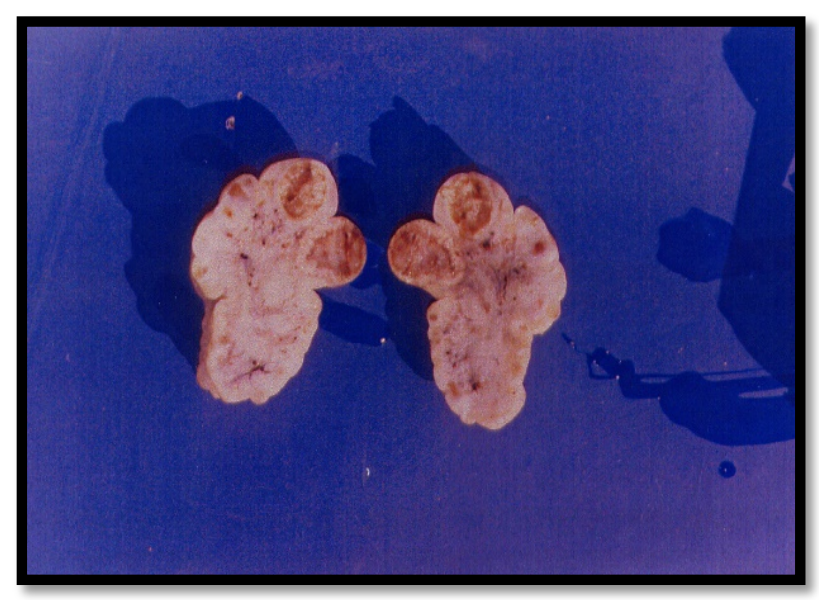

Figure 11. Plexiform haemangioma C.S. Note the tumor on the surface and its brownish color. 


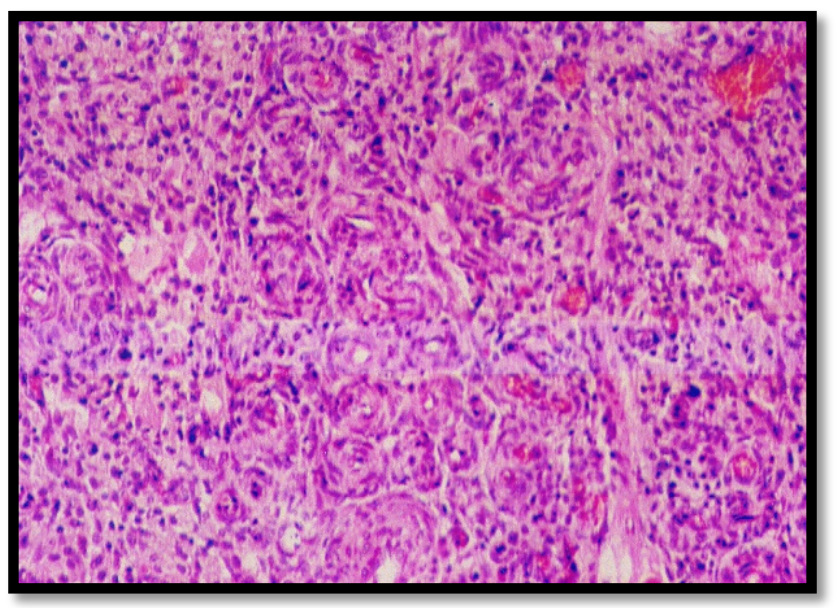

Figure 12. Plexiform haemangioma. (Photo micrograph). Note the tumor formation of blood vessels, fibroblasts and collagen fibers.

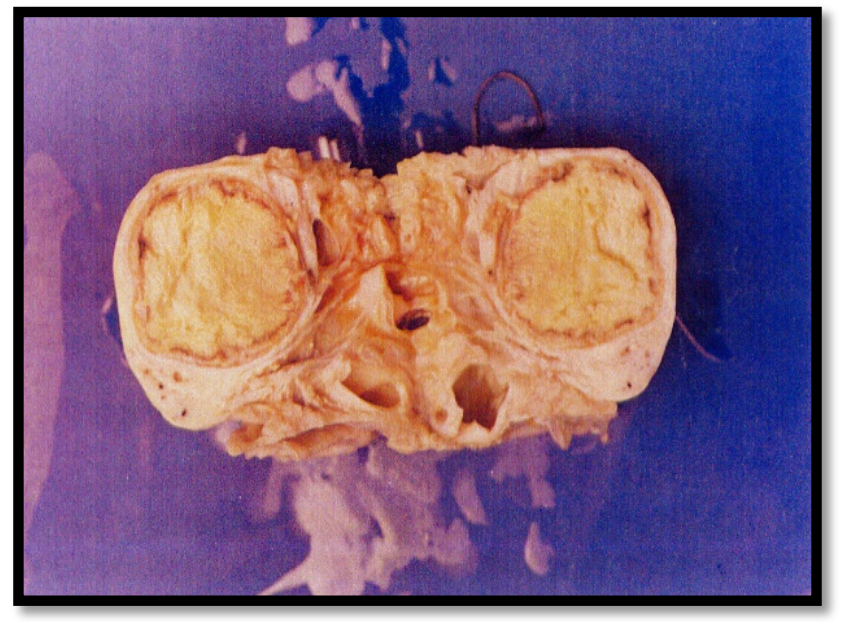

Figure 13. Ovarian abscess. Notice the presence of ovarian hyperplasia and contain pus surrounded by a thick wallet and the disappearance of ovarian tissue.

\section{Discussion}

Previous reports have shown that the camels have low reproductive efficiency [18]. Hence, it is of value to investigate the causes of this drop by studying the reproductive disorders in camels, as these reproductive defects are considered the main cause of infertility in dromedary camels. The present study showed that, $14.2 \%$ prevalence of gross ovarian lesions in camels in Al-Ahsa region was observed without evidence of any relevant clinical symptoms in ante mortem examination. The rate of incidence of ovarian lesions recorded in this study was lower than the previously reported by [13] [16] and higher than that recorded by [19] [20] who found that the incidence of ovarian affections of she-camel was $10.4 \%$ and $7 \%$ respectively. This difference in ratios may be due to several factors including, differences in nutrition, ages of the studied group of camels, temperatures and location of the study area, as well as genetic factors [21] [22]. In this study, the total ratio of the prevalence of ovarian hypoplasia in slaughtered ca- 
mels in Al-Ahsa abattoirs was $4.85 \%$. Grossly the hypoplastic ovaries were in the form of small, thin and firm structure without any small follicles. This value is in agreement with that reported by [16] but higher than the finding of [20] [23] and lower than the values reported by [9]. This variation in the occurrence of ovarian hypoplasia may be due to hereditary characters and other environmental factors such as body condition and nutritional factors. Cystic ovaries were detected in the present study with an incidence rate of, $3.8 \%$, and $2.38 \%$ for follicular and luteal cysts respectively. Ovarian cysts have been described in dromedaries [1] [14] [22] [24]. However, cystic ovary conditions in dromedary are not well documented as in cattle or other domestic animals. It has been mentioned that the presence of cysts is an indication of ovulation failure that may occur due to inadequate release of luteinizing hormone (LH) [18] [25]. The average incidence rates of follicular and luteal cysts in she-camels in Al-Ahsa region recorded in this study is in agreement with that previously reported by [19] and vary from that observed in other countries [20] [21].

In the present study, three types of ovarian tumors were observed, classified as, Fibromas (0.952\%), Dermoid cysts $(1.42 \%)$, and hemangioma, $(0.470 \%)$. The overall prevalence of the incidence of ovarian tumors shown in this study was $2.842 \%$. These findings are consistent with the previous observations of [16]. Several authors had previously reported dermoid cysts in the camel's ovary [14] [22] [26]. However the incidence of ovarian hemangioma and fibromas in camels was only recorded by [16]. Ovarian abscesses were detected in this study with an incidence of (1\%) of all the collected samples. Generally, oophoritis is rare in domestic animals. However suppurative inflammation of the ovary was previously reported in dromedaries, leading to the formation of ovarian abscesses [9]. The ovarian abscess observed in this study may be from either a direct extension or hematogenous spread of infection in the uterus or uterine tubes.

\section{Conclusion}

In conclusion, this study indicates that cystic ovaries and ovarian hypoplasia are the more common ovarian disorders in female dromedary camels in Al-Ahsa region, and may impair the reproductive efficiency in this species. Therefore, more studies should be carried out to investigate the clinical and endocrinological aspects of these disorders and their relation to camel infertility.

\section{Acknowledgements}

The authors acknowledge the College of Veterinary Medicine at King Faisal University and College of Science at Imam Abdul Rahman Bin Faisal University, Dammam for providing research facilities.

\section{Conflicts of Interest}

The authors report no conflicts of interest. 


\section{References}

[1] Nawito, M.F. (1967) Some Reproductive Aspects in the Female Camel. Warsaw Agricultural University, Faculty of Veterinary Medicine, Warsaw.

[2] Hegazy, A., Youseff, H. and Selim, S. (1979) Bacteriological and Histopathological Studies on Endometritis of the Camel. Journal of the Egyptian Veterinary Medical Association, 39, 81-97.

[3] Dafalla, E., Al Eknah, M. and Gameel, A. (1991) Unilateral Ovarian Agenesis in a Camel. Reproduction in Domestic Animals, 26, 266-269. https://doi.org/10.1111/j.1439-0531.1991.tb01537.x

[4] Al-Ani, F., Zenad, K. and Al-Shareefi, M. (1992) Reproduction Failure in Female Camels during an Abattoir Survey. Indian Journal of Animal Sciences, 62, 553-555.

[5] Ali, A., El Sanousi, S., Al Eknah, M., Gameel, A., Dafalla, E., Homeida, A. and Radwan, Y. (1992) Studies on the Infundibular Cysts of the Uterine Tube in Camel (Camelus dromedarius). Revue délevage et de médecine vétérinaire des pays tropicaux, 45, 243-253. https://doi.org/10.19182/remvt.8911

[6] Ali, A., Al-sobayil, F.A., Tharwat, M., Al-Hawas, A. and Ahmed, A. (2010) Causes of Infertility in Female Camels (Camelus dromedarius) in Middle of Saudi Arabia. Journal of Agricultural and Veterinary Sciences, Qassim University, 2, 59-66.

[7] Ali, A., Derar, R., Al-Sobayil, F., Al-Hawas, A. and Hassanein, K. (2015) A Retrospective Study on Clinical Findings of 7300 Cases (2007-2014) of Barren Female Dromedaries. Theriogenology, 84, 452-456. https://doi.org/10.1016/j.theriogenology.2015.03.039

[8] Tibary, A. and Anouassi, A. (2000) Recent Advances in Camelid Reproduction.

[9] Vaughan, J. and Tibary, A. (2006) Reproduction in Female South American Camelids: A Review and Clinical Observations. Small Ruminant Research, 61, 259-281. https://doi.org/10.1016/j.smallrumres.2005.07.015

[10] Tibary, A. and Anouassi, A. (1997) Reproductive Disorders of the Female Camelidae. Theriogenology in Camelidae: Anatomy, Physiology, BSE, Pathology and Artificial Breeding. Actes Editions: Institut Agronomique et Vétérinaire Hassan II, 317-368.

[11] Wernery, U., Kinne, J. and Schuster, R.K. (2014) Camelid Infectious Disorders: OIE (World Organisation for Animal Health).

[12] Hussein, F. and Hassieb, M. (1989) Morphopathological Studies on the Ovaries, Oviducts and Uteri from Camels with Cystic Ovaries. Assiut Veterinary Medical Journal (Egypt), 21, 184-186.

[13] Ribadu, A., Ogwu, D., Njoku, C. and Eduvie, L. (1991) An Abattoir Survey of Female Genital Disorders of Imported Camels (Camelus dromedarius) in Kano, Nigeria. British Veterinary Journal, 147, 290-292. https://doi.org/10.1016/0007-1935(91)90054-Q

[14] El-Khouly, A., Abd-El-Gadar, F. and Tawfic, M. (1991) Histopathological and Histochemical Studies on Ovarian Congenital Anatomical Defects and Some Ovarian Tumors in Camels. Zagazig Veterinary Journal (Egypt), 19, 558-572.

[15] Hussein, N.A. and Saad, A.M. (2017) Pathological Disorders of the Ovaries and Uterine Tubes in Camels (Camelus dromedarius) Slaughtered at Tamboul Abattoir, Sudan. Journal of Camel Practice and Research, 24, 251-256. https://doi.org/10.5958/2277-8934.2017.00043.1

[16] Al-Afaleq, A.I., Hegazy, A.A., Hussein, M.F. and Al-Dughaym, A.M. (2012) Pathological Disorders of the Female Reproductive System in Slaughtered Camels ( $\mathrm{Ca}$ - 
melus dromedarius) in Saudi Arabia. Comparative Clinical Pathology, 21, 245-251. https://doi.org/10.1007/s00580-010-1086-2

[17] Bancroft, J. and Gamble, M. (2008) Theory and Practice of Histological Techniques. 6th Edition, Churchill Livingstone, London.

[18] Skidmore, J. and Adams, G.P. (2003) Recent Advances in Camelid Reproduction. International Veterinary Information Service, Ithaca.

[19] Hamouda, M.M., Al-Hizab, F.A. and Hasseeb, M.M. (2011) Pathologic Studies on Ovarian Abnormalities in Nagas (Camelus dromedarius) in Al-Ahsa, Saudi Arabia. Scientific Journal of King Faisal University (Basic and Applied Sciences), 12, 265-276.

[20] Dawod, A. and Hamed, T.E. (2018) Ovarian Reproductive Affections in She-Camels. Journal of Veterinary Science \& Technology, 9, 562. https://doi.org/10.4172/2157-7579.1000562

[21] Tibary, A., Fite, C., Anouassi, A. and Sghiri, A. (2006) Infectious Causes of Reproductive Loss in Camelids. Theriogenology, 66, 633-647.

https://doi.org/10.1016/j.theriogenology.2006.04.008

[22] El-Wishy, A. (1996) Genital Abnormalities in Camels (Camelus dromedarius). 163-174.

[23] Melaku, S.K., Melaku, M., Feyisa, A., Demissie, T., Regassa, F., Mekonnen, G., Almaw, G., Tessema, T., Kassa, T. and Dawo, F. (2015) Pathological and Bacteriological Study on Abnormalities of Female Internal Reproductive Organ of Camelus dromedarius Slaughtered at Akaki Abattoir, Ethiopia. American-Eurasian Journal of Scientific Research, 10, 193-202.

[24] El-Khouly, A., Abd-El-Gadir, F. and Ontabli, A. (1991) Studies on Ovarian Teratoma in Camels. Zagazig Veterinary Journal (Egypt), 19, 475-486.

[25] Skidmore, J., Billah, M. and Allen, W. (1995) The Ovarian Follicular Wave Pattern in the Mated and Non-Mated Dromedary Camel (Camelus dromedarius). Journal of Reproduction and Fertility. Supplement, 49, 545.

[26] Purohit, N., Chouhan, D., Dudi, P. and Vyas, U. (1989) Dermoid Cysts in Camels. British Veterinary Journal, 145, 89-90.

https://doi.org/10.1016/0007-1935(89)90015-8 